\title{
Photophysical characterization of chosen Ln(III) macromolecular complexes
}

\author{
Krzysztof Staninski and Stefan Lis \\ Department of Rare Earths, Faculty of Chemistry, Adam Mickiewicz University, \\ Grunwaldzka 6, Poznań, 60-780, Poland
}

\begin{abstract}
Spectral characterization of N,N'-Bis(2,4-dihydroxobenzylidene)1,2-diaminobenzene (DHDA) complexes with chosen f- and d-metal ions are described. Physico-chemical properties of a series of complexes were studied in methanol solution using UV-VIS, IR and fluorescence spectroscopy. It was found that the excitation and fluorescence spectra of DHDA in water and methanol after being exposed to ultraviolet radiation, show very obvious photochromism. The formation of $1: 1$ complexes between $4,4^{\prime}, 4^{\prime \prime}, 4^{\prime \prime \prime}$ (porphine-5,10,15,20-tetrayl)-tetrakis benzoic acid, $\left(\mathrm{TCPPH}_{2}\right)$ and $\mathrm{La}(\mathrm{III}), \mathrm{Eu}(\mathrm{III})$ and $\mathrm{Yb}$ (III) in methanolic solution, with the use of the spectrophotometric and spectrofluorimetric methods. The conditional stability constants of the complexes were studied by monitoring the spectral changes of energy and intensity of $\mathrm{Q}$ bands of the porphyrin.
\end{abstract}

\section{INTRODUCTION}

A lot of Schiff bases and their complexes have been tested from the point of view of their possible applications in biology, biochemistry and medicine $[1,2]$. Results of the study of the interactions of these compounds with lanthanide ions and d-electron group metals suggest a possibility of formation of stable complexes in solution [3, 4]. The Schiff base derivatives obtained as a result of condensation of salicylic aldehyde and appropriate amines are characterised by increased delocalisation of $\pi$-electrons in the molecule thanks to the presence of unpaired electrons in hydroxyl groups. This property opens new possibilities of their application for producing new electroluminescence materials. Moreover, it has been established that some Schiff bases and their complexes show specific photochemical properties such as photo- and thermochromizm and nonlinear optical properties $[5,6]$.

This paper presents results of a study on the kinetics of complex formation between selected lanthanide ions and d-electron metals with $\mathrm{N}, \mathrm{N}^{\prime}-\mathrm{Bis}(2$, 4-dihydroxobenzylidene)1,2-diaminobenzene (DHDA) and the photochromism of these compounds. Moreover, the emission properties of the complexes of selected lanthanides with $4^{\prime}, 4^{\prime \prime}, 4^{\prime \prime \prime}$-(Porphine5,10,15,20-tetrayl)-tetrakis(benzoic acid) have been studied and their stability constants in methanol have been determined. Both of the selected ligands, i.e. DHDA and $\mathrm{TCPPH}_{2}$, contain aromatic luminophores in their structure, which make them applicable in electroluminescent [7] and chemiluminescent [8] studies due to facility of red-ox initiated excitation. Their lanthanide(III) complexes play an important role in these phenomena and can be detected by hot electron chemistry and time-resolved electrochemiluminescence down to the picomolecular level $[9,10]$.

\section{EXPERIMENTAL}

All the reagents used were analytical grade. Synthesis and purification of DHDA were described earlier [11]. DHDA and its complexes were irradiated with a low-pressure UV lamp. Spectroscopic measurements were made on a UV-VIS spectrometer Shimadzu 2401/PC and a modified spectrofluorimeter MPF-3. The solutions were prepared with spectral grade methanol. $4^{\prime}, 4^{\prime \prime}, 4^{\prime \prime \prime}$-(Porphine-5,10,15,20tetrayl)-tetrakis(benzoic acid), ( $\mathrm{TCPPH}_{2}$ ), 98\% FLUKA, were used without additional purification.

Lanthanide nitrates: $\mathrm{La}(\mathrm{III}), \mathrm{Eu}(\mathrm{III})$, and $\mathrm{Yb}$ (III) were obtained in the reaction of their oxides $(99.9 \%$, made at the Rare Earths Laboratory, Faculty of Chemistry, Adam Mickiewicz University) with nitric acid (puriss) FLUKA. The salts $\mathrm{Cu}\left(\mathrm{NO}_{3}\right)_{2}, \mathrm{Co}\left(\mathrm{NO}_{3}\right)_{2}$ and $\mathrm{Zn}\left(\mathrm{NO}_{3}\right)_{2}$ (puriss, FLUKA) were used after recrystallisation.

\section{RESULTS AND DISCUSSION}

As has been shown earlier DHDA in methanol forms complexes with both lanthanides and d-electron metals [11]. According to absorbance measurements of an alcohol solution of DHDA with proper metal salts added, the equilibrium in the complex formation reaction is achieved relatively slow.

Figure 1 presents the absorption spectra of an exemplary system of Eu(III)-DHDA recorded at different time after reagents mixing. The spectra show that with the progress of complex formation the intensity of the band at $\lambda=365 \mathrm{~nm}$ decreases, while that of the band at $\lambda=254 \mathrm{~nm}$ increases. Kinetic measurements of the complex formation were performed for $\lambda=365 \mathrm{~nm}$ on a Shimadzu 2401/PC spectrophotometer working in the time course. The kinetic curves of the decay of the band at $\lambda=365 \mathrm{~nm}$ accompanying formation of the 


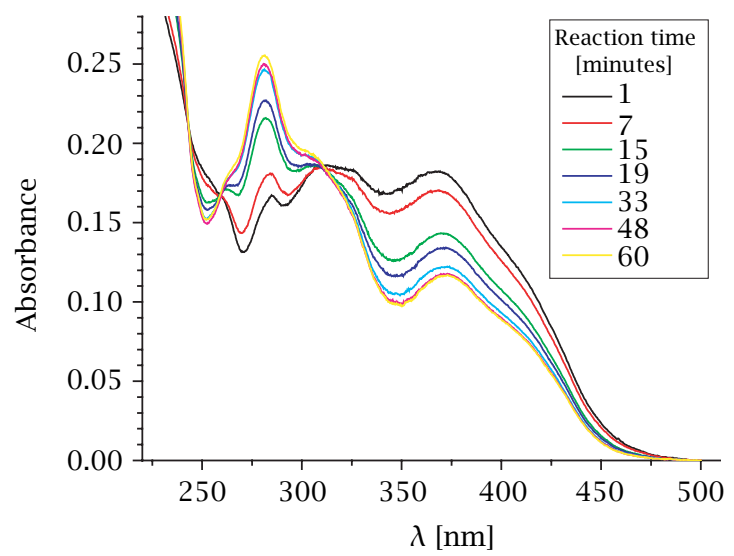

Figure 1. Changes of the absorption spectra after mixed of the europium salt and DHDA solutions. Concentrations of reagents were $10^{-4} \mathrm{~mol} / \mathrm{l}$.

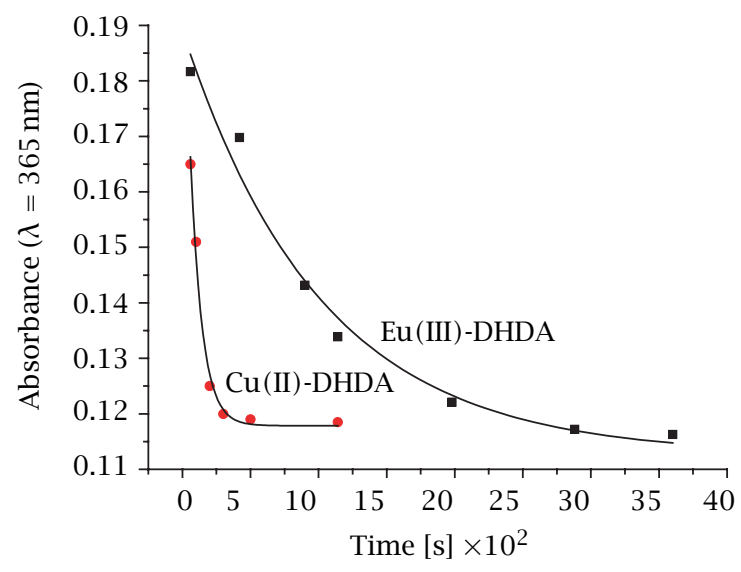

Figure 2. Kinetic curves decay of absorption band at $365 \mathrm{~nm}$ in methanolic solutions of $\mathrm{Eu}$ (III)-DHDA and $\mathrm{Cu}$ (II)-DHDA complexes.

complexes Eu(III)-DHDA and $\mathrm{Cu}(\mathrm{II})$-DHDA are shown in Figure 2.

It is evident that the complex $\mathrm{Cu}$ (II)-DHDA forms faster than that with europium ion. The tendency is apparent for all metal ions studied. Assuming that the decrease in the intensity of the band at $\lambda=365 \mathrm{~nm}$ is proportional to the amount of the $1: 1$ complex and that the kinetic curve represents the first order exponential decay, the decay rate constants have been found for all systems studied (Table 1).

The rate of complex formation with d-electron metals is in general higher than in the case of lanthanide(III) complexes. The slow achievement of equilibrium in the systems Ln(III)-DHDA can be a result of a strong tendency of lanthanide ions solvation by the methanol and water molecules containing hardly polarised oxygen atoms. The kinetics of displacement of the alcohol or water molecules from the coordination sphere of lanthanides by the ligand containing soft nitrogen atoms
Table 1. Kinetic formation constants for chosen $\mathrm{d}$ - and $\mathrm{f}$ electron metal-DHDA complexes.

\begin{tabular}{lc}
\hline Complex & Kinetic formation constants $\left[\mathrm{s}^{-1}\right]$ \\
\hline La(III)-DHDA & $1.5 \pm 0.1 \cdot 10^{-3}$ \\
Eu(III)-DHDA & $9.9 \pm 0.1 \cdot 10^{-4}$ \\
$\mathrm{Yb}(\mathrm{III})$-DHDA & $7.2 \pm 0.2 \cdot 10^{-4}$ \\
$\mathrm{Cu}(\mathrm{II})$-DHDA & $1.2 \pm 0.1 \cdot 10^{-2}$ \\
$\mathrm{Zn}(\mathrm{II})-\mathrm{DHDA}$ & $1.5 \pm 0.2 \cdot 10^{-2}$ \\
$\mathrm{Co}(\mathrm{II})-\mathrm{DHDA}$ & $1.4 \pm 0.1 \cdot 10^{-2}$ \\
\hline
\end{tabular}

is slower than from the spheres of easier polarised delectron ions.

3.1. Photochromic properties. The photochromic properties of Schiff bases and their derivatives are a result of intramolecular proton transfer and disturbance of the keto-enol equilibrium [5, 12]. It has been shown that an important factor determining the photochromic properties of these compounds is the spatial structure of the molecule, in particular the distances between the chromophore centres and the proton donating $-\mathrm{OH}$ groups and $-\mathrm{N}=$. According to the theoretical calculations with the program HyperChem 6.0 based on the method A1, in the molecules of DHDA these distances are relatively small (3.6 A between the oxygen molecules in the phenol rings), which should favour the phenomenon of photochromism (Figure 3).

The results obtained for methanol solutions of DHDA irradiated with $\lambda_{\mathrm{ex}}=270 \mathrm{~nm}$ have fully confirmed the above assumptions. Figure 5 presents the absorption spectra of DHDA in methanol recorded at $10 \mathrm{~s}$ after each irradiation. The intensity of the absorption band at $365 \mathrm{~nm}$ decreases and that at the band at $265 \mathrm{~nm}$ increases. The changes in the intensity of the band at $\lambda=365 \mathrm{~nm}$ have been used for investigation of the enol-ketone transition in DHDA solutions (Figure 4).

Assuming that changes in the absorption band intensity are proportional to the concentration changes of the enol species, the rate constant of reaching the enol-ketone equilibrium was calculated (Figure 5). Photochromic studies were performed for all complexes studied. The solutions of $1: 1$ metal-DHDA complexes proved photochemically stable. Even long-time irradiation with the wavelengths froma wide UV-VIS range $(250-400 \mathrm{~nm})$ did not produce significant changes in the spectra of the complexes studied. This observation confirms that the photochromic properties of DHDA are related to the intramolecular proton transfer from the phenyl ring to the nitrogen atom. Metallation of the system $\mathrm{N}_{2} \mathrm{O}_{2}$ in the Schiff base molecule blocks the donor nitrogen atoms preventing transformation of the enol into ketone species.

Chemistry of porphines and their metal complexes, similarly as that of Schiff bases, has been intensively studied because of their role in analytical and biological systems [8, 13-15]. Increasing interest in of porphines 


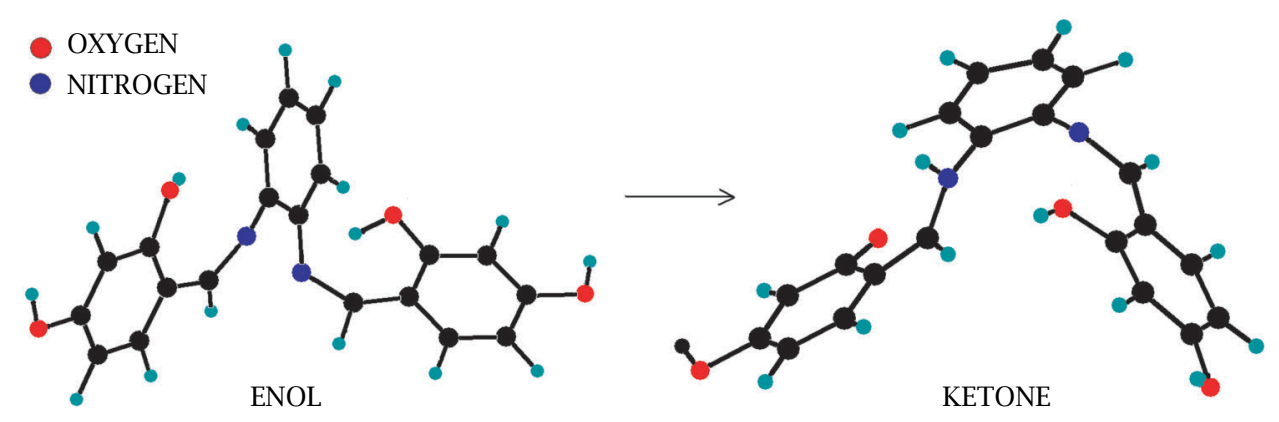

Figure 3. Molecular structure analysis of the photochromism of DHDA.



Figure 4. Absorption spectral changes for DHDA with irradiation $10^{-4} \mathrm{~mol} / \mathrm{l}$ methanolic solution of DHDA.

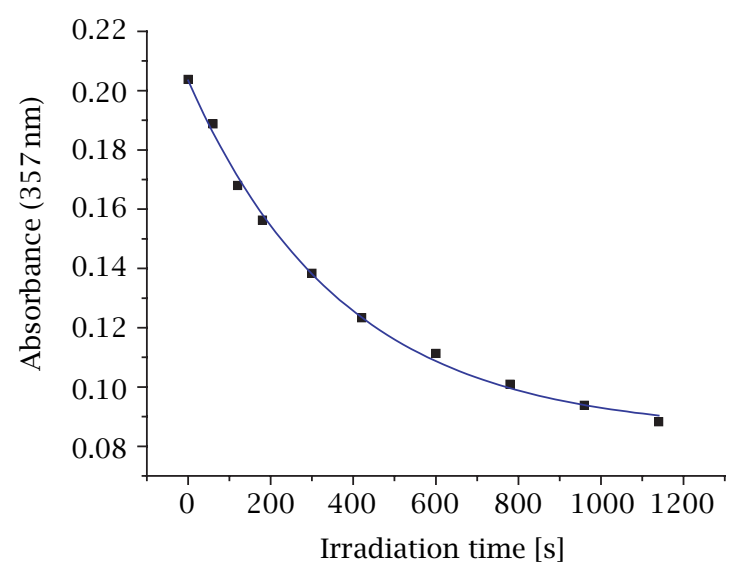

Figure 5. Decay kinetic curve of the irradiated methanolic solution of DHDA, $10^{-4} \mathrm{~mol} / \mathrm{l}$ for absorption band $\lambda=$ $355 \mathrm{~nm}$.

and their metal complexes being involved in components of biochemical transformations in a living cell has stimulated study of systems containing porphines with ionic groups such as $\mathrm{COO}^{-}, \mathrm{SO}_{3}{ }^{-}$or $=\mathrm{N}^{-} \mathrm{CH}_{2}{ }^{+}$.

This paper reports a study of formation of $1: 1$ complexes between $4,4^{\prime}, 4^{\prime \prime}, 4^{\prime \prime \prime}$-(porphine-5,10,15,20-

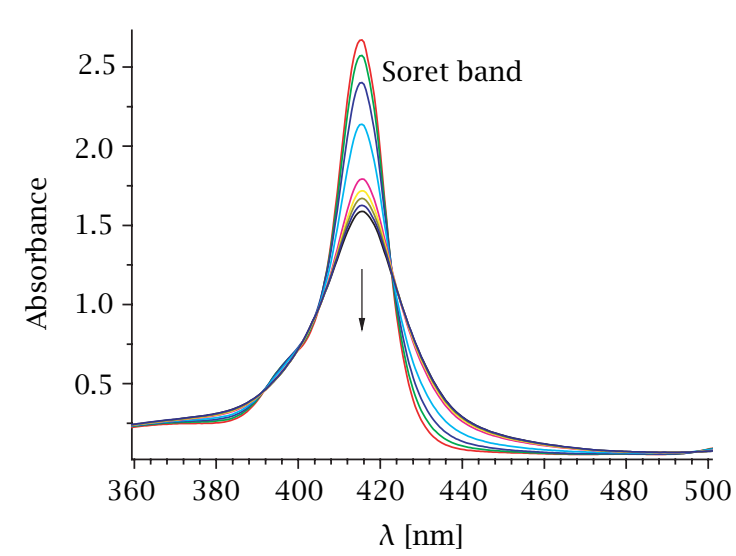

Figure 6. Absorption spectra of the $\mathrm{TCPPH}_{2}$ in methanol as a function of europium ions concentration. The $\mathrm{Eu}(\mathrm{III}): \mathrm{TCPPH}_{2}$ molar ratio had carried out since $1: 0.5$ to $1: 3$, methanolic solution, $\left(\mu=0.01, \mathrm{NaClO}_{4}\right)$.

tetrayl)-tetrakis benzoic acid $\left(\mathrm{TCPPH}_{2}\right)$ and lanthanide ions: $\mathrm{La}(\mathrm{III}), \mathrm{Eu}(\mathrm{III})$ and $\mathrm{Yb}(\mathrm{III})$, by the spectrophotometric method. Suppression of the emission of $\mathrm{TCPPH}_{2}$ after addition of lanthanide(III) ions in methanolic solution was also studied.

The absorption spectra of porphyrins are extremely sensitive to such processes as metallation, protonation, ring oxidation or dimerization. The spectra shown in Figures 6 and 7 illustrate characteristic spectral changes that accompany porphyrin metallation without changes in the $\mathrm{D}_{2 \mathrm{~h}}$ symmetry.

The equilibrium constants of the complexes studied were determined by monitoring the changes in the energy and intensity of the $\mathrm{Q}$ bands of porphyrin (Figure 7). Spectral changes in these bands in the range of $470-700 \mathrm{~nm}$ indicating the $\mathrm{Ln}(\mathrm{III})-\mathrm{TCPPH}_{2}$ complex formation and have been used for determination of stability constants by the earlier presented method [8, 14].

The stability constants were calculated using the following equation:

$$
\begin{aligned}
\mathrm{C}_{\mathrm{Ln}} \mathrm{C}_{\mathrm{L}} / \mathrm{A}_{\mathrm{LnL}}= & {\left[\mathrm{C}_{\mathrm{Ln}}+\mathrm{C}_{\mathrm{L}}-\left(\mathrm{A}_{\mathrm{LnL}} / \varepsilon_{\mathrm{LnL}}\right)\right] } \\
& \times\left(1 / \varepsilon_{\mathrm{LnL}}\right)+1 /\left(\beta \varepsilon_{\mathrm{LnL}}\right)
\end{aligned}
$$




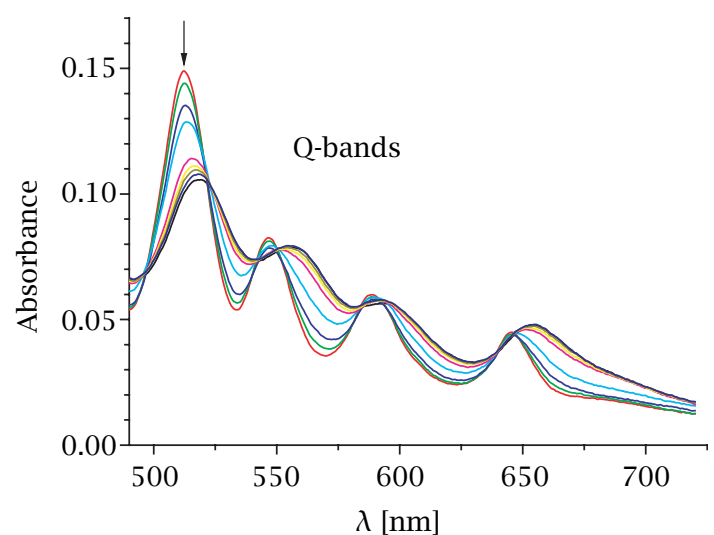

Figure 7. Spectral changes of $\mathrm{Eu}(\mathrm{III})-\mathrm{TCPPH}_{3}$ in the $\mathrm{Q}$-bands range methanolic solution, $\left(\mu=0.01, \mathrm{NaClO}_{4}\right)$.

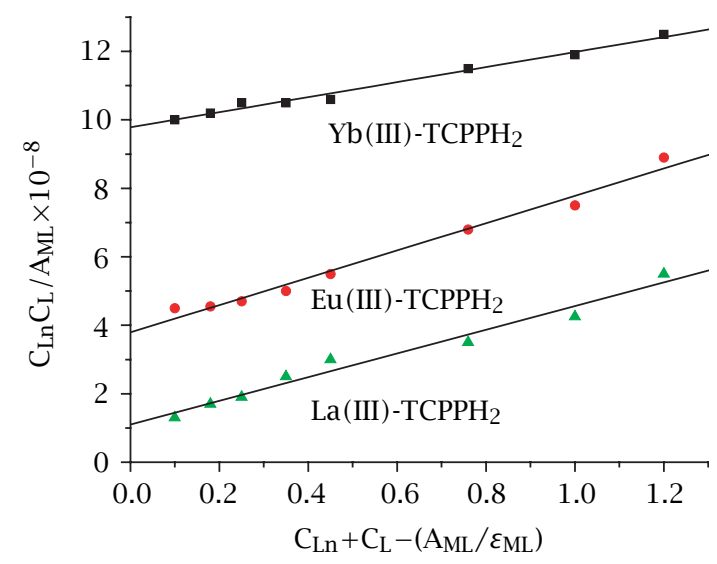

Figure 8. A plot of $\mathrm{C}_{\mathrm{Ln}} \mathrm{C}_{\mathrm{L}} / \mathrm{A}_{\mathrm{LnL}}$ versus $\mathrm{C}_{\mathrm{Ln}}+\mathrm{C}_{\mathrm{L}}-\left(\mathrm{A}_{\mathrm{LnL}} / \varepsilon_{\mathrm{LnL}}\right)$ to measure stability constants of $\mathrm{Ln}(\mathrm{III})-\mathrm{TCPPH}_{2}$.

Table 2. Stability constant values and degree of quenching of fluorescence in lanthanide(III) complexes of $\mathrm{TCPPH}_{2}$.

\begin{tabular}{|c|c|c|}
\hline Complex & $\log \beta$ & \% suppression \\
\hline $\mathrm{La}(\mathrm{III})-\mathrm{TCPPH} 2$ & $3.7 \pm 0.2$ & 17 \\
\hline $\mathrm{Eu}(\mathrm{III})-\mathrm{TCPPH}{ }_{2}$ & $3.2 \pm 0.1$ & 34 \\
\hline $\mathrm{Yb}(\mathrm{III})-\mathrm{TCPPH}_{2}$ & $2.8 \pm 0.2$ & 43 \\
\hline
\end{tabular}

where:

$\mathrm{C}_{\mathrm{Ln}}$-total lanthanide ion concentration,

$\mathrm{C}_{\mathrm{L}}$-total $\mathrm{TCPPH}_{2}$ concentration,

$\mathrm{A}_{\mathrm{LnL}}=\mathrm{A}_{\mathrm{T}}-\mathrm{A}_{\mathrm{L}}\left(\mathrm{A}_{\mathrm{T}}\right.$ and $\mathrm{A}_{\mathrm{L}}$ total absorbance and absorbance of the free ligand in the studied spectral region respectively),

$\varepsilon_{\text {LnL }}$-molar absorption coefficient of the $1: 1$ complex $\beta$-conditional stability constant of the complex of Ln(III)-TCPPH $\mathrm{H}_{2}$

Plots of $\mathrm{C}_{\mathrm{Ln}} \mathrm{C}_{\mathrm{L}} / \mathrm{A}_{\mathrm{LnL}}$ versus $\mathrm{C}_{\mathrm{Ln}}+\mathrm{C}_{\mathrm{L}}-\left(\mathrm{A}_{\mathrm{LnL}} / \varepsilon_{\mathrm{LnL}}\right)$ are almost linear (Figure 8 ) indicating that only the $1: 1$ complexes are formed in the conditions of the study (Figure 8).

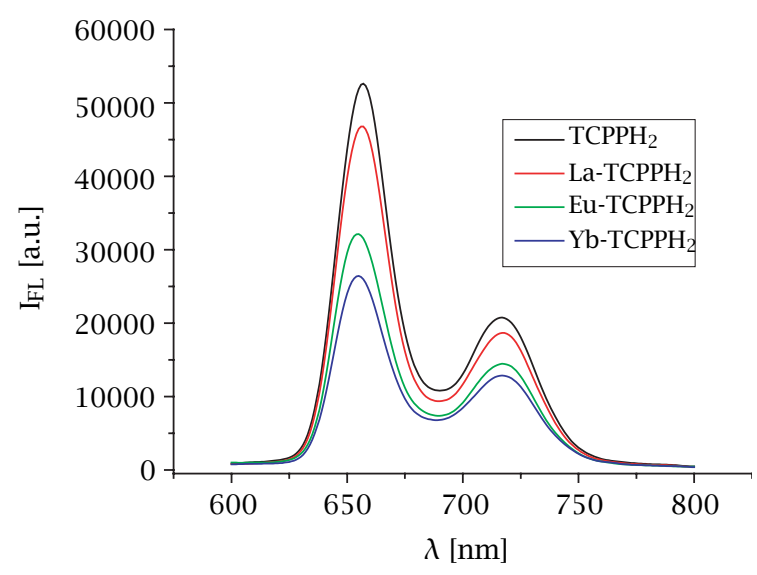

Figure 9. Luminescence spectra of the methanolic solutions of $\mathrm{TCPPH}_{2}$, $\mathrm{La}^{-\mathrm{TCPPH}} \mathrm{P}_{2}$, Eu-TCPPH $\mathrm{H}_{2}$ and $\mathrm{Yb}-\mathrm{TCPPH}_{2}$ $\left(\lambda_{\mathrm{exc}}=410 \mathrm{~nm}\right)$, molar ratio $\mathrm{Ln}(\mathrm{III}): \mathrm{TCPPH}_{2}=1: 1$, concentration of $\mathrm{TCPPH}_{2}=1.5 \times 10^{-5}$.

In different conditions ( $\mathrm{TCPPH}_{2}$ in excess) formation of other more complicated oligomeric structures has been detected by changes in intensity of the Soret band (Figure 6). The reciprocal of the slope of the line yielded the correction value of $\varepsilon_{\mathrm{LnL}}$, used to replot the above relation. The slope/intercept ratio of the resulting plot gives the $\beta$ value (Table 2).

The complex formation of the lanthanides with $\mathrm{TCPPH}_{2}$ was studied by the spectrofluorimetric method, monitoring the porphine emission in the range 600-800 $\mathrm{nm}$.

Excitation into the ligand at $410 \mathrm{~nm}$ (Soret band) yields the red emission. Figure 9 shows the emission spectra of $\mathrm{TCPPH}_{2}$ and the three complexes studied.

The emission spectra revealed a decrease the intensity of the bands at 655 and $720 \mathrm{~nm}$ for the components at $1: 1$ molar ratio.

A similar phenomenon of emission quenching has been observed for monocarboxyphenyl porphyrins after addition rare earth ions [16]. This effect was not observed in the presence of d-electron metal ions coordinated to the porphine ring. This indicates that the suppression happens due to the heavy atom effect and the presence of lanthanide ions increases deactivation of the electronic levels through intersystem crossing by increasing the spin-orbit coupling.

\section{Conclusions}

The DHDA molecule shows an obvious photochromism as result of the keto-enol equilibrium in this system.

Complexes of DHDA with d-electron metal ions $(\mathrm{Cu}$, $\mathrm{Zn}, \mathrm{Co})$ present about one order of magnitude higher values of the kinetic formation constants, than the felectron metal ions ( $\mathrm{La}, \mathrm{Eu}, \mathrm{Yb})$. 
In the case of $\operatorname{Ln}(\mathrm{III}): \mathrm{PCPPH}_{2}=1: 1$ complexes, a red fluorescence of the ligand is suppressed by $\mathrm{Ln}(\mathrm{III})$ ions. The observed quenching is more effective when the charge density of the lanthanide ion is higher.

\section{REFERENCES}

[1] N. W. Alcock and D. H. Busch, Chem. Rev. 94 (1994), 585.

[2] J. P. Glusker, T. Wagner, C. E. Afshar, H. L. Carrel, U. Englert, and H. P. C. Hogenkamp, Inorg. Chem. 38 (1999), 1785.

[3] L. Canali and D. C. Sherrington, Chem. Soc. Rev. 28 (1999), 85.

[4] K. E. Splan, A. M. Massari, G. A. Morris, S.-S. Sun, E. Reina, S. T. Nguyen, and J. T. Hupp, Eur. J. Inorg. Chem. (2003), 2348-2351.

[5] S. Mitra and N. Tamai, Chem. Phys. Lett. 282 (1998), 391.

[6] J. Zhao, B. Zhao, J. Z. Liu, A. Ren, and J. Feng, Chem. Lett. (2000), 268-269.

[7] P. Canty, L. Väre, M. Hakansson, A.-M. Spehar, D. Papowsky, T. Ala-Kleme, J. Kankare, and S. Kulmala, Anal. Chim. Acta 453 (2002), 269.
[8] K. Staninski, M. Kaczmarek, S. Lis, and M. Elbanowski, J. Solid State Chem. 171 (2003), 208.

[9] S. Kulmala, A. Kulmala, T. Ala-Kleme, and J. Pihlaja, Anal. Chim. Acta 367 (1998), 17.

[10] S. Kulmala and K. Haapakka, J. Alloys Comp. 22 (1995), 502.

[11] K. Staninski, S. Lis, and Marek Pietraszkiewicz, J. Fluorescence 2005, accepted for publication.

[12] J. Zhao, B. Zhao, J. Liu, W. Xu, and Z. Wang, Spectr. Acta Part A 57 (2000), 149.

[13] M. Makarska, S. Radzki, and J. Legendziewicz, J. All. Comp. 341 (2002), 233.

[14] S. Radzki, J. Legendziewicz, J. Sokolnicki, and R. Wilgusz, J. All. Comp. 300-301 (2000), 439.

[15] K. M. Kadich, K. M. Smith, and R. Guilard (eds.), The Porphyrin Handbook, Vols. 1-10, Academic Press, New York, 2000.

[16] O. A. Serra, C. R. Neri, Y. Iamamoto, E. J. Nassar, P. S. Calefi, S. A. Cicillini, and C. M. C. P. Manso, J. Inc. Phen. Mac. Chem. 35 (1999), 271. 


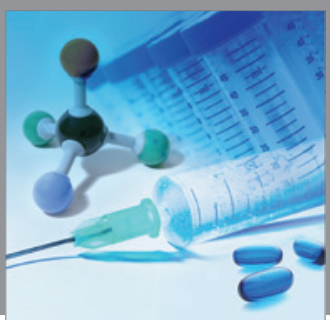

International Journal of

Medicinal Chemistry

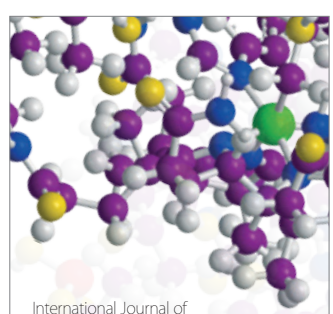

Carbohydrate Chemistry

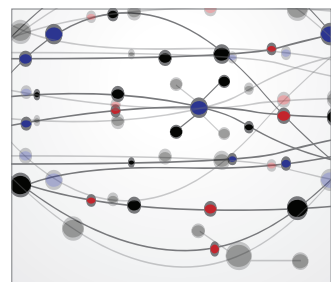

The Scientific World Journal
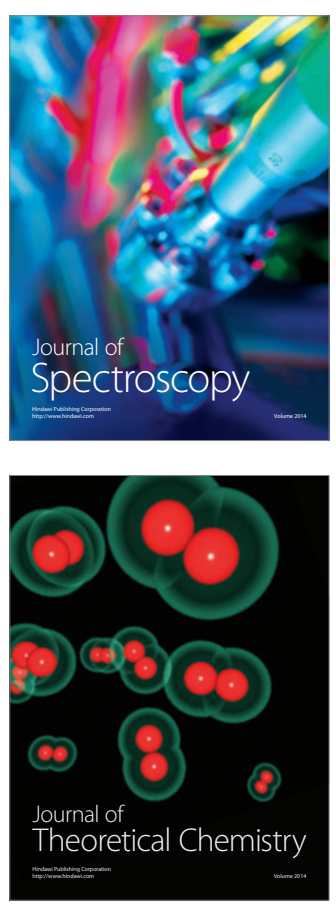
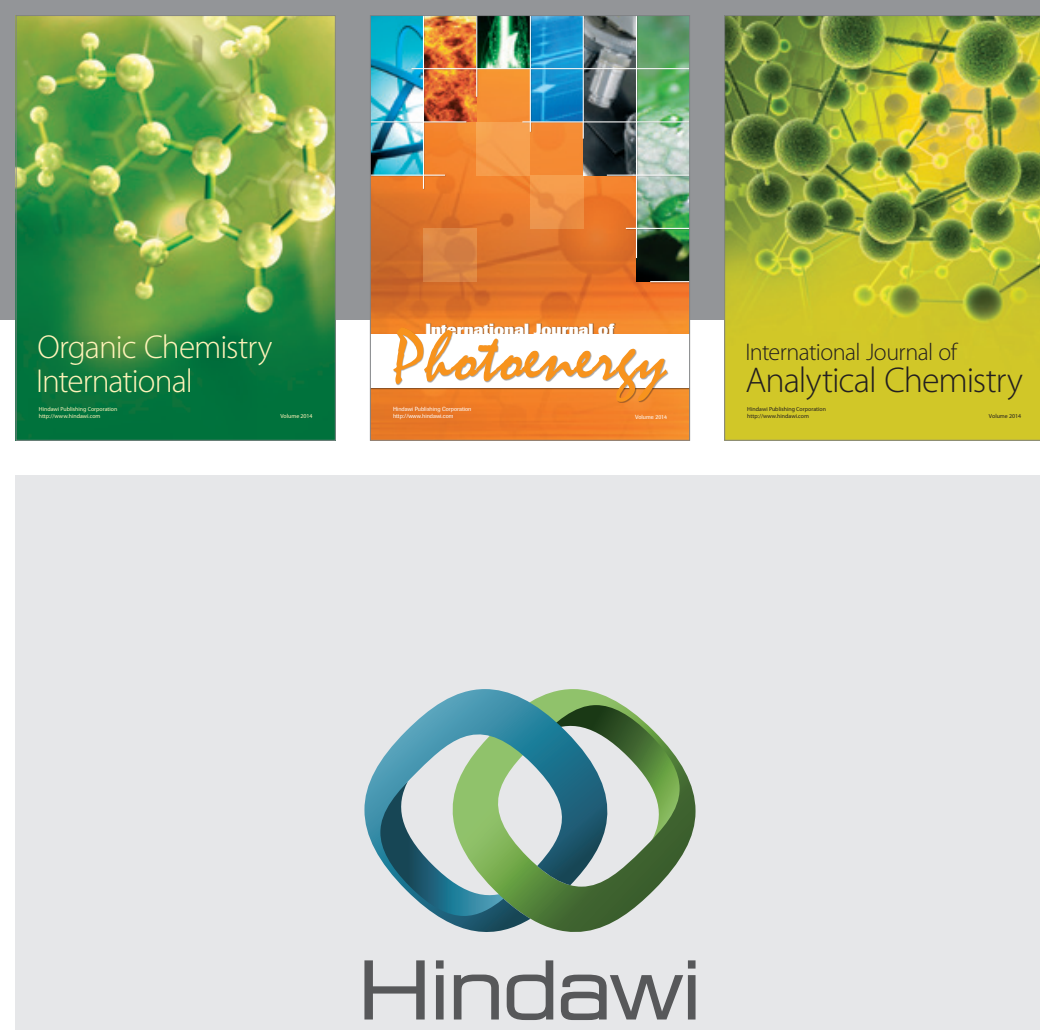

Submit your manuscripts at

http://www.hindawi.com
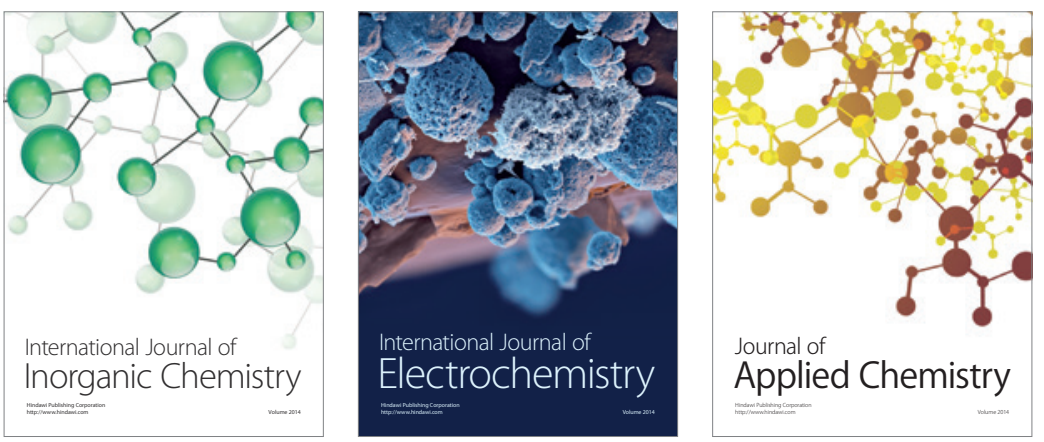

Journal of

Applied Chemistry
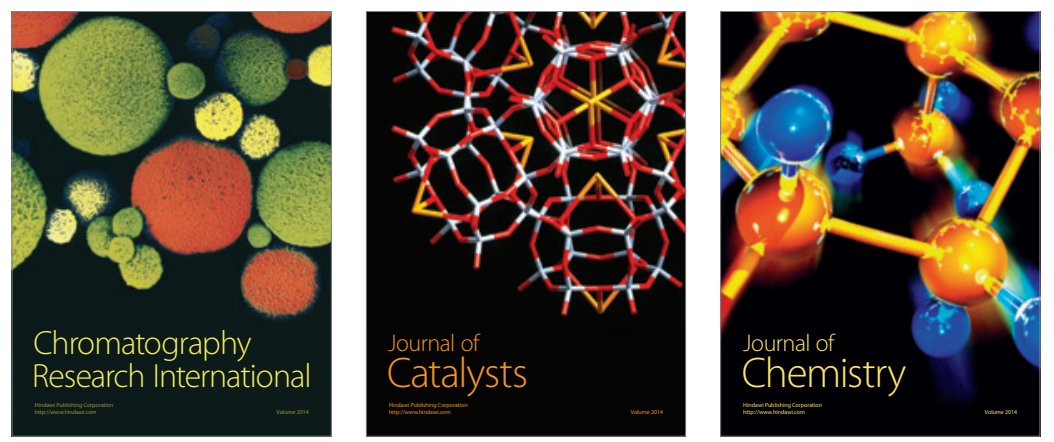
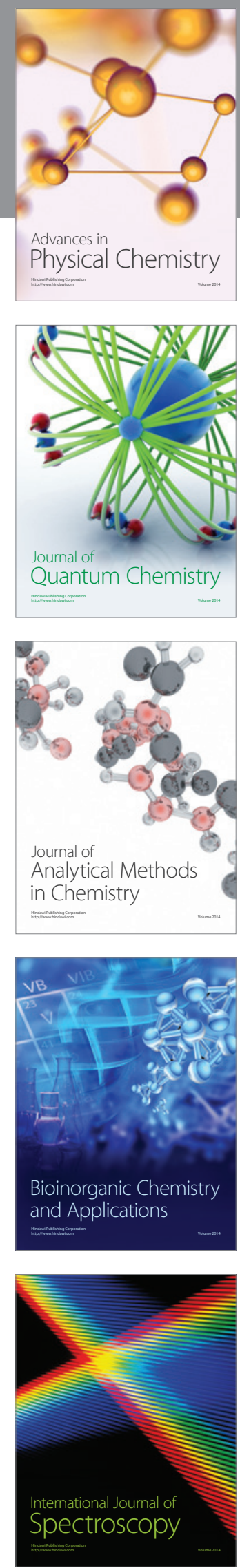